\title{
LA ALIMENTACIÓN COMO ACCIÓN, UNA EXPERIENCIA PERFORMÁTICA
}

\author{
Nuria Faba Muñoz \\ Estudiante de doctorado de la Universidad Politécnica de Valencia
}

\begin{abstract}
Food, throughout history, has been the object of being represented by various artistic techniques and disciplines. As is the case with video or action art. Artists who resort to action to express an idea have multiple elements such as: space, time, sound, light, objects, spectators and their own body. These artistic actions, in which improvisation and cadence are added to the articulation of these elements, are what many curators, artists and theorists call performances. The purpose of this article is to make known what performance consists of and who are the key performers, specifically those who have worked in the line of food and the actions that derive from it. Everyday actions such as shopping, cooking, eating, or socializing. All this is understood through the works of a selection of performing artists such as: Bobby Baker, Martha Rosler, Rirkirit Tiravanija, Antoni Miralda, Àlvar Calvet, Patty Chang or Romira de Novellis, among others. Each performer offers a very particular vision implicit in the daily action linked to food.
\end{abstract}

Keywords: food, performance, artistic experience, action art, performers.

Resumen: La alimentación, a lo largo de la historia, ha sido objeto de ser representada por diversas técnicas y disciplinas artísticas. Como es el caso del vídeo o del arte de acción. Los artistas que recurren a la acción para expresar una idea, cuentan con múltiples elementos como: el espacio, el tiempo, el sonido, la luz, los objetos, los espectadores y su propio cuerpo. Estas acciones artísticas, en las que a la articulación de estos elementos se les suma la improvisación y la cadencia, son las denominadas por muchos curadores, artistas y teóricos como performances. El propósito del presente artículo es dar a conocer en qué consiste la performance y quienes son los artistas performers clave, en concreto los que han trabajado en la línea de la alimentación y en las acciones que de esta se derivan. Acciones cotidianas como el comprar, el cocinar, el comer o el relacionarse. Todo ello es entendido a través de las obras, de una selección de artistas performers como: Bobby Baker, Martha Rosler, Rirkirit Tiravanija, Antoni Miralda, Àlvar Calvet, Patty Chang o Romira de Novellis, entre otros. Cada performer, ofrece una visión muy particular implícita en la acción cotidiana vinculada a la alimentación.

Palabras clave: alimentación, performance, experiencia artística, arte de acción, performers.

Citar como: Faba Muñoz, N. (2022). "La alimentación como acción, una experiencia performática". En: Actas del III Congreso Internacional sobre Patrimonio Alimentario y Museos. 25-26 noviembre, 2021, Valencia, España. pp. 185-203. https://doi.org/10.4995/EGEM2021.2021.13290 


\section{Introducción}

El tema alimentario y el propio acto de comer, han sido abordados a lo largo de la historia por las humanidades de una manera transversal, ofreciendo una gran variedad de posicionamientos teóricos, estéticos y críticos. Porque comer no es sólo alimentarse, el acto de comer puede ser considerado como un acto político, de compromiso con los seres que nos rodean y con el planeta. Considerado como vehículo de acercamiento social, político y económico. Durante el acto de comer se generan una multitud de sucesos y temas a tratar, ajenos o no a la temática alimentaria como pueda ser: la tradición, la identidad y la sociabilización, entre otros. Es lógico que desde el arte se muestre su interpretación a todos estos aconteceres, desde disciplinas clásicas hasta disciplinas más actuales, propias de la acción y el vídeo. La irrupción del vídeo en el arte, se muestra tanto como una herramienta de documentación de la acción como obra final.

En el presente artículo se pretende ofrecer una visión sobre la alimentación actual desde el arte, en concreto desde la performance. Para ello es relevante realizar un recorrido por conceptos fundamentales para su comprensión, se intentará definir qué es una acción, una performance, el papel del performer. Se pretende realizar un repaso por los artistas performers que han abordado esta disciplina, tratando de mostrar la evolución de la performance y su implicación en el tema que nos acontece: La alimentación.

Como se muestra en la bibliografía, se quiere mostrar los trabajos de artistas performers que han trabajado en la línea de la alimentación y con las acciones que se generan a su alrededor. Acciones cotidianas como el comprar, el recolectar, el cocinar, el comer o el relacionarse. Todo ello es entendido a través de las obras, de una selección de artistas performers como: Bobby Baker, Martha Rosler, Rirkirit Tiravanija, Antoni Miralda, Àlvar Calvet, Patty Chang o Romira de Novellis, entre otros. Cada artista, en su trabajo performático, ofrece una visión muy particular implícita en la acción cotidiana, vinculada a la alimentación. La huella de esta acción puede ser muy diversa, suscitando reacciones muy dispares en los espectadores lejanas a la indiferencia.

Se realizará un análisis del trabajo personal de performance ¿Comes conmigo?, que presenté como artista performer en julio de 2021 relativo al trabajo de investigación doctoral sobre la alimentación actual. A través de esta acción performática se pretende abordar aspectos relativos a el qué, el cómo, el porqué y el con quién, de la alimentación actual. En concreto se abordará el acto cotidiano de comer. El objetivo principal de esta performance consiste en poder visualizar la resiliencia alimentaria y la resiliencia social respecto al acto cotidiano de comer.

\section{Objetivos}

Como principal objetivo se pretende:

- Ofrecer la visión particular del arte sobre la alimentación a través de la performance.

Existen otros objetivos que lo secundan:

- Definir conceptos clave para la comprensión del arte de acción, en concreto de la performance.

- Recopilar fuentes referenciales que muestren el trabajo de diversos artistas clave en el campo de la performance, que abarquen temas relativos a la alimentación.

- Mostrar el trabajo artístico personal y de investigación sobre la alimentación actual. 


\section{La performance como expresión artística, origen y desarrollo}

\subsection{La performance, origen etimológico}

Para poder comprender en qué consiste, quizás sería conveniente realizar un repaso por el origen etimológico de la palabra performance. Revisando las investigaciones de varias figuras teóricas como la estadounidense Amelia Jones o como la historiadora de arte británica RoseLee Goldberg, recogidas en el libro de Juan Albarrán: Performance y arte contemporáneo, discursos, prácticas y problemas. (Albarrán, 2019), sobre el estudio de la performance.

Seguidamente se da paso a parafrasear el significado del término: si bien existen varios significados para el sustantivo performance, tanto en inglés como en francés, tales como: actuación, espectáculo, representación, etc, para los hispanohablantes el término, adquirido del inglés, se ha identificado como arte de performance.

Para el diccionario de la Real Academia Española se destaca la siguiente definición:

"Actividad artística que tiene como principio básico la improvisación y el contacto directo con el espectador"

Conforme se describe en el libro de Juan Albarrán (anteriormente mencionado), las investigaciones de Amelia Jones van más allá, dando paso a realizar un análisis etimológico sobre el verbo, el sustantivo y el adjetivo, en la lengua inglesa (to perform, performance y performative), del que podemos concluir sus usos a través de la historia.

\footnotetext{
"To perform: hacer, hacer bien, entretener. Etimología: inglés medio, del anglo-francés parfumer, alteración de performer, parfurnir, de par-, per-, <totalmente>( del latín per-)+ furnir, <completar>. Primer uso conocido, siglo XIV.
}

Performance: la ejecución de una acción; representar un personaje de una obra; la eficiencia con la que tiene lugar una acción. Primer uso conocido siglo XV.

Performing: < de, relativo a, o constitutivo de una parte ( como el arte dramático) que implica la actuación frente al público>; ejemplo: las <artes performativas>. Primer uso conocido, 1889.

Performative: el acto de hacer o representar o <de, relativo a o constitutivo de un arte (como el arte dramático) que implica la participación de un público>; en lingüística, <relativo a una expresión que sirve para efectuar una operación o que constituye la ejecución del acto específico en virtud de su declaración>. primer uso conocido, en 1995."

Siguiendo con Albarrán: si bien se contextualiza el origen del vocablo inglés performance en el siglo XIV, en un periodo marcado por el incipiente surgimiento del ocio en sociedades burguesas protocapitalistas; es en el siglo XIX cuando el término es utilizado para designar formas del teatro profesionalizado, en un contexto de sociedades más complejas. Y en el siglo XX es cuando surgen nuevos sentidos relacionados con la teoría del lenguaje.

Pero si queremos hablar más exactamente de cuando se generalizó el concepto performance, cabría decir que fue a finales de los 70. Hasta la fecha se habían utilizado otros conceptos para designar otras propuestas artísticas no objetuales ahora vinculadas a la performance, estas propuestas se conocen bajo los siguientes conceptos: arte de acción, el happening, event, body art, body works o art corporel. 
A finales de los 70 el concepto de la performance se desvincula del papel que un actor realiza en el teatro y pasa a ser un concepto primordial para hablar el presente, pasado y futuro de prácticas que nutren y amplían las artes visuales.

En 1979 la historiadora de arte RoseLee Goldberg a través de su libro Performance. Live Art 1909 to the Present. (Goldberg, 1979) y posteriormente ampliado en 1988 con una variación en el título: Performance Art. From Futurism to the Present, (Goldberg, 1988) que fue traducido al castellano en 1996, como búsqueda de conciencia histórica y buscándole un sitio dentro de las instituciones. Goldberg da un nuevo enfoque al estudio de la performance a través de asumir su deuda con las vanguardias. Es por ello que sitúa como antecedentes lejanos el futurismo y el dadaísmo junto con algunas experiencias constructivistas, surrealistas y las innovaciones teatrales de finales del siglo XIX. Surgieron figuras como John Cage y Merce Cunninghan y posteriormente entre los años 60 y 70 surgen artistas que trabajan en el movimiento artístico Fluxus, el posminimalismo, la danza y el arte conceptual.

La performance se alimenta del arte de vanguardia, del teatro, de la danza de las artes visuales... se convierte en un arte transdisciplinar. Por tanto surge como ruptura con el arte burgués y se presenta como una práctica de proyectos estético-políticos con tinte progresista que intenta institucionalizarse.

La performance por su carácter presencial se describe como un arte vivo, en tiempo real, que conjuga la cotidianidad con el arte, de una manera híbrida.

En 2011 y como respuesta irónica a la investigación histórica y al afán de posicionar la performance dentro del marco institucional por parte de Goldberg, surge un proyecto pseudohistoriográfico y ficticio titulado This is the Performance Art, de la artista Mel Brimfield. Su trabajo es presentado a través de vídeos, fotografías, escritos, re-enactments entre otros documentos que desvirtúan a través del empleo de la parodia, algunos datos históricos sobre la performance añadiendo de su propia cosechas datos ficticios. This is the Performance Art, representa una sátira hacia la figura del crítico de arte de carácter pedante que ha asistido a numerosas performances y que se pronuncia a través de otros autores. Brimfield también utiliza anacronismos, relaciones imposibles y el humor como eje central invitando a reconsiderar la veracidad de las fuentes utilizadas para los escritos de historiadores de arte como Goldberg. Quizás parezca un ataque hacia el trabajo historiográfico pero en realidad a mi entender lo que presenta es un cuestionamiento de todo lo que implica incluir a la performance en la categoría de arte elevado, qué se omite, qué prácticas son realmente performance, el tono mesiático...todo ello es cuestionado a través de la sátira.

"...Parecía que imitar las estrategias curatoriales de las instituciones y sus materiales explicativos era una manera eficaz de destacar las infravaloradas relaciones con el activismo,el teatro, la comedia, la música y la danza en la historia del live art"

Investigando en el origen del concepto, encontramos la investigación sobre los enunciados performativos que posteriormente desembocaron en las teorías de la performatividad de género generadas por Judith Butler, a finales de los años 80. Se cimientan en parte en la discusión entre los filósofos John L. Austin y Jacques Derrida sobre dichos enunciados performativos. Fue el filósofo John L. Austin el padre del adjetivo "performativo", el cual empleó este término en 1955 y posteriormente compilaría en su libro titulado Cómo hacer cosas con palabras, (Austin, 1962), en el que muestra sus teorías sobre los actos del habla, diferenciando dos enunciados: el enunciado 
constatativo y el enunciado performativo. El enunciado es performativo cuando no se describe nada, estando en un contexto circunstancial se realiza un acto. Posteriormente amplía el concepto de performativo también para los enunciados constatativos ya que estos también dependen de las condiciones. Austin formula una taxonomía de las diferentes formas que se tiene de hacer algo al decir o enunciar algo, distinguiendo tres actos: el acto locutivo (decir algo es hacer algo), el acto ilocutivo (al decir algo estamos haciendo algo) y el acto perlocutivo (porque decimos algo, estamos haciendo algo) y es en el acto ilocutivo donde se reconoce el acto esencial de la palabra.

Los enunciados performativos pues no registran o distinguen nada, no son ni verdaderos ni falsos y el acto de expresar la oración es realizar la acción y dependen de las condiciones o circunstancias.

Aunque no en su investigación no consiguió resultados claros, sí que fue interesante su influencia en las investigaciones posteriores de otros teóricos de campos transversales.

Para el filósofo posestructuralista Jacques Derrida, pese a valorar la recuperación por parte de Austin del carácter pragmático que posee el lenguaje, de su materialidad y de su gran poder para provocar cambios. Para Derrida la gran carga performativa no reside en el emisor, como decía Austin, sino de que este enunciado haya sido anteriormente dicho y ya escuchado por otros. Por tanto su sentido el enunciado es decodificable, alterable, se puede prestar a la repetición y sobrevive al emisor.

Tanto para Austin, Derridas como para Butler, lo performativo queda vinculado al discurso, al lenguaje. Por tanto es Diana Taylor quien realiza una distinción entre lo performativo y lo performático. Taylor defiende que el término performático se refiere a la forma adjetivada no discursiva de la performance.

Sin embargo en el mundo del arte contemporáneo esta distinción no ha tenido gran aceptación, puesto que el adjetivo performativo es usado de manera indistinta para cualquier trabajo relacionado con la performance, aunque sí que es verdad que en un sentido más corporal que discursivo es el llamado performance art.

La performance por tanto se consolida a finales de los años 80 como consecuencia de estudios teóricos y prácticos con carácter interdisciplinar. Debido a esta renovación, de la amplitud que podía abarcar el término, se pudo trasladar la performance al ámbito del teatro, de la danza, el performance art, incluso un acto cotidiano como un concierto o el acto de hacer la compra y como en el caso de mi investigación al acto de comer. Todos estos actos implican la interacción entre las personas que comparten el espacio y el tiempo. Por tanto todo ello provoca un desplazamiento epistemológico superando las limitaciones de las disciplinas académicas tradicionales.

Schechner en diálogo con el antropólogo Victor Turner, propuso como principal característica de la performance el concepto de restauración de la memoria. Con ello hacía referencia a los rituales, hábitos y rutinas que se suelen reproducir de una manera prácticamente consciente, en las que no existe una autoría, ni un original estable con lo cual estas acciones o rituales no son simples copias. En estos rituales el performer no se comporta como si fuera del todo él o ella, sino que está en un estado casi ajeno a su persona. Esta colaboración entre Scechner y Turner, crea una base antropológica sobre el Estudio de Performance que se desarrollará posteriormente como son los dramas sociales, memorias corporizadas y ritos. 
Durante los años 90 en el contexto anglosajón se fueron consolidando los Estudios de la Performance en los ámbitos académicos. Sin embargo en 2012 surge cierta resistencia por parte del traductor Rafael Segovia Albán en su traducción del libro al castellano de Schechner Performance Studies. An Introduction (Schechner, 2002). En la traducción decidió utilizar otros términos para sustituir la palabra performance, como: función, representación, actuación...entre otras, fue entendido como un gesto de resistencia hacia una palabra proveniente del inglés, un idioma hegemónico capaz de colonizar otros contextos. La crítica propuso que en vez de traducir el texto de Schechner, quizás hubiese sido más acertado redactar un libro desde el contexto del pensamiento mexicano.

Performance es un vocablo que según muchos teóricos entre ellos Anne Johnson, que no pueden traducirse al castellano.

Tal y como defiende Albarrán en su libro Performance y arte contemporáneo, discursos, prácticas y problemas (Albarrán, 2019), hasta hace relativamente poco tiempo, contados investigadores de la historia del arte y de los fenómenos artísticos dentro del marco de un territorio tan interdisciplinar como es la performance, han adquirido visibilidad. Albarrán propone que quizás se debería reciclar o actualizar los marcos teóricos y las metodologías empleadas por la disciplina humanística que focaliza su mirada más en la marginación del cuerpo que en los rituales, los activismos o actos de la vida cotidiana.

Según la investigación del performer y académico Bartolomé Ferrando en su libro El arte de la performance, elementos de creación, (Ferrando, 2009) parte de la definición del término performance, como término inglés cuyo origen proviene de la palabra francesa parformer que a su vez se deriva de la palabra latina per-formare. Término que abarca un gran abanico de formas de hacer, de actuar o de intervenir que desembocan en otras manifestaciones muy dispares entre sí. Pluralidad que propicia a prácticas que se multiplican, se solapan, interfieren unas con otras, se cruzan incluso llegando a desbordarse a sí mismas.

Se podría concluir que la performance en su intento por definirla ofrece cierta resistencia, ya que posee un carácter espectral, la performance ofrece la dualidad de estar siempre presente a la vez que en otro lugar.

Pero sí que se podría intentar comprender sus cualidades, características al igual que los elementos de los que se nutre. Para ello a continuación se da paso a hablar los factores temporales y espaciales, del cuerpo de la performance, de la idea, del alejamiento de la representación, de la relación comunicativa del performer con los asistentes, de la interacción con el público y su participación así como la importancia del contexto.

Para Bartolomé Ferrando existen modos de hacer dentro del arte de acción estos son: la performance, el happening, el evento y la maniobra. Happening o performance happening es cuando importa el hecho participativo y maniobra cuando se refiere a lo imperceptible o lo mínimo que se manifiestan en algunas performance. Siguiendo con Bartolomé se puede entender mejor la performance si conocemos los factores y elementos de los que se nutre. 


\subsection{Factores y circunstancias de los que se nutre la performance}

Para que una performance sea exitosa, es decir: que esté bien conseguida y que tenga interés para el espectador, depende de diversos parámetros como de la energía que mueve y genera como de la atención que suscita en los demás.

La performance es eficaz cuando es portadora de una energía, fuerza interior o un grado de intensidad elevado que deriva de la atención y de los siguientes factores y elementos: el espacio, el tiempo, el cuerpo, la no representación, la idea, el contexto, la participación, el hecho comunicativo y la energía que se genera.

En toda performance se produce un acoplamiento entre el espacio y el cuerpo, el cuerpo se prolonga por un espacio envolvente. El espacio pasa a formar parte activa de la acción, es tan importante ese espacio que envuelve al cuerpo o al objeto como el propio cuerpo, el espacio pasa a ser presencia haciéndose perceptible. Una performance se puede adueñar del espacio invadiéndolo y haciéndolo suyo, sin importar sus dimensiones.

Dentro del factor espacial, la iluminación juega un papel fundamental, ya que enfatiza aquel gesto o acción que el performer quiere acentuar. Incluso hay performance que se sirven de espacios virtuales, con imágenes pregrabadas con las que el sujeto interactúa en un territorio visual y sonoro. La presencia del espacio es un factor importante, el espacio es la huella de la acción.

Realizar un recorrido en el espacio es hacerlo simultáneamente en el tiempo. Cada acción está compuesta por tiempos distintos, cada una tiene su propia latencia, su propia cadencia y de su propio espacio específico. Es por ello por lo que Bartolomé Ferrando afirma que múltiples espacios-tiempo nos miran desde la unicidad de la acción. En el performer un ejercicio importante es conocer, el ritmo, la latencia personal de uno mismo para tomar consciencia del propio tiempo. Alejando pensamientos para que ocurra el vacío. Otro ejercicio interesante consiste en la repetición de un gesto, de esta manera el tiempo se percibe suspendido en sí mismo, se genera una temporalidad diferente. Tomar consciencia del tiempo subjetivo implica una mirada interna de la cadencia personal, esta cadencia es transmitida por empatía al espectador.

En la mayoría de los casos, una acción no tiene una secuencia lógica, está expuesta a interrupciones y cambios de ritmo. Se puede alternar entre un ritmo acelerado y un ritmo lento, pudiendo llegar a ese silencio rítmico que es la pausa, como un silencio vivo pero a su vez cargado de energía, en el que todo ocurre.

En la mayoría de las performances el tiempo no es lineal, pasa a ser circular, a superponerse, a entrar en bucle pero con variaciones, es un tiempo expuesto a que sucedan cosas.

Pero más allá del factor espacio-tiempo existe un factor determinante que es la presencia del cuerpo del performer. El cuerpo del performer al integrarse en la práctica consigue ser el resultado de la misma. El artista se expone en conjunción con la obra, es la obra o parte muy importante de ella.

Hablar del cuerpo del performer es hablar de la unidad entre el cuerpo y la mente, ya que el pensamiento se construye a través del cuerpo, pero el cuerpo del performer se deja llevar, deja que fluyan acontecimientos, para poder sentir con mayor intensidad la acción que está realizando. 
El cuerpo deambula por el espacio temporal dejándolo fluir al relacionarse con otros objetos, siendo estos una prolongación del propio cuerpo. El cuerpo también lo constituye el llenar el espacio de murmullos, carraspeos, gritos o palabras. Existe una cierta elasticidad del cuerpo del performer respecto a los límites corporales, en un ejercicio de descubrimiento y autodescubrimiento. Muchos performers utilizan prácticas de vaciado a modo de purificación corporal y mental antes de realizar una performance como: ayuno, abstinencia sexual o ejercicios de concentración, entre otros. Permitiendo, en muchos casos que el cuerpo se mimetizara con el espacio, por ejemplo como es el caso de la artista performer Ana Mendieta su cuerpo se mimetiza y se funde con la naturaleza, en otros casos el performer se mimetiza con la música, sus gestos y guiños se convierten en música muda pero visible.

El cuerpo en otras ocasiones es mostrado como soporte de la intervención, convirtiéndose en materia que soportaba heridas, mordeduras, quemaduras...o como soporte de otros objetos que se derramaban o se dejaban caer sobre el mismo con todo esto el público empatiza y puede llegar a sentir las sensaciones de dolor, de repulsión o puede sentir el erotismo, la ternura entre otras sensaciones. El cuerpo sin límites, en otros casos se ha dejado conocer como un cuerpo biotecnológico en el que el artificio y la naturaleza están distanciados por una ligera línea.

La audiencia de una performance se encuentra con un performer que interviene en el espacio-tiempo relacionándose con otros elementos o con su propio cuerpo. Este performer no representa sino que fluye y genera acontecimientos inesperados, generando verdad. Se resiste a la teatralidad, a la representación, que en algunas performance este distanciamiento está más marcado que en otras. Existe una cierta voluntad de alejamiento de la representación, se busca nuevos modos de relación entre el performer y los objetos, alejándose de las normas habituales de proceder o de uso. La performance hace un guiño al desorden pero manteniéndose distante del caos. La performance rompe con las normas tradicionales de relación, de uso, de ritual pero dentro de unos límites que en cierto modo no están descontrolados del todo. Porque la distancia entre el arte y la vida es ínfima.

Por otro lado, la performance no nace de la nada, una performance nace de una idea. Como mínimo existe una intención, una idea como punto de partida que en la performance puede derivar en ideas secundarias propias de la influencia de factores como: el espacio-tiempo, la interacción con los objetos, con el propio cuerpo y con el público. En toda esta articulación de elementos se genera la energía necesaria para que la performance sea eficaz.

Lo que está claro es que existe una intención, por parte del performer, de comunicar, normalmente generando empatía en el otro, con la intención de hacer sentir y activando la capacidad de imaginar. En la intención de comunicar no está implícito el deseo de que el receptor llegue a alguna conclusión similar a la que pueda tener el emisor, a mi modo de ver en la intención del emisor va un " ahí lo dejo y haz lo que quieras con ello".

Sí que es cierto, que para que una performance sea eficaz también ha de estar muy interiorizada la idea en el emisor, ha de ser cierta y veraz para el performer.

En la performance es especialmente significativo el carácter ambiguo que esta posea, ello hará que sea posible una multitud de lecturas, aunque se corre el riesgo de que si es demasiado ambiguo no se llegue a ninguna interpretación por ello es importante el contexto en el que se materialice la acción. 
En cuanto a la participación, hay performers que consideran importante poder invitar al público a intervenir, pero para otro grupo de artistas performers piensan que no es necesario ya que por el simple hecho de que estén presentes en la acción ya están participando en ella.

\subsection{Fuentes referenciales de la performance y alimentación}

Es necesario conocer figuras claves y representativas del arte de acción aunque la mayoría de ellos no trabajasen en torno al tema de la alimentación. En el presente artículo se intenta realizar un recorrido por sus trabajos más significativos enfatizando en aquellas figuras que posteriormente han llegado a trabajar en torno al tema alimentario en sus performances.

\subsubsection{Contextualización del surgimiento de las figuras clave de la performance}

Para poder contextualizar a todos estos artistas referenciales de la performance actual, la investigadora y docente de Historia del arte Amalia Martínez, realiza un repaso por la historia del arte. En su libro De Andy Warhol a Cindy Shermann, (Martínez, 2000) describe de una manera muy concisa como fue el nacimiento de un arte de acción como consecuencia de un rechazo, por parte de los artistas emergentes, hacia la mercantilización de la obra de arte y como repulsa hacia una sociedad de consumo.

Fué en la segunda mitad de la década de los años 60, cuando un grupo de jóvenes artistas surgen con ideas revolucionarias respecto a la trayectoria materialista y mercantilizada de la obra de arte. Quisieron romper con el culto burgués por las artes tradicionales como la pintura o la escultura. Por esta razón surgen conceptos como: instalación, ambiente, happening, performance, arte del cuerpo, arte de la tierra, entre otros. Nuevas formas artísticas vinculadas a la influencia temporal y a la vida. surge un arte de investigación sobre su propia naturaleza como lenguaje y con su contexto social, político y económico. Surge el arte del concepto para manifestarse como idea. Pero en años posteriores todo este arte fue absorbido por el propio sistema al que se oponían.

En la segunda mitad del siglo XX, la actividad artística ya no se identifica con la creación de objetos, ha pasado a identificarse con la creación de situaciones en las que el espectador se implica de forma activa o de forma pasiva, siendo integrante o testigo de la misma. Hay que reconocer que el accionismo aunque pertenece a la segunda mitad del siglo XX sus cimientos son deudores de las vanguardias.

Es fundamental resaltar como figura del Accionismo norteamericano a John Cage, que fue precursor de un arte experimental en el que a modo de un todo, articulaban diversas disciplinas como: la danza, la música, imágenes proyectadas, la poesía y la pintura. Todo el conjunto estaba regido por el azar, la improvisación y la simultaneidad. Ejemplo de ello fue la obra que realizó en colaboración con Merce Cunningham en 1952 titulada Theater Piece N11.

Otro referente es el grupo japonés Gutai, los cuales fundieron varios elementos provenientes del vanguardismo pictórico con otros elementos de la caligrafía y con el teatro oriental. Cuadros que resultan del gesto de danzar con los pies cargados de pintura, salpicando sobre un papel extendido en el suelo.

En Europa como pioneros del arte de acción se destaca el grupo Fluxus en el que participaron artistas como George Maciunas, Wolf Vostell, Josep Beuys, Ben Vautier, Henry Flynt y Nam June Paik. 
Ven Vautier decía que Fluxus es el continente para las ideas, como modo de presentarlas, unas veces será la escritura, la fotografía...lo equiparaba a la continuación de la maleta de Duchamp.

En España el referente más importante como iniciador del arte de acción o accionismo fue el grupo ZAJ (fundado por Walter Marcheti y Juan Hidalgo y a los que posteriormente se uniría Esther Ferrer).

En Viena se fundó en 1965 el Grupo de accionismo Vienés, integrados por Otto Muehl, Herman Nitsch, Günter Brus y Rudolf Schwarzkogler, incluyeron en sus manifestaciones artísticas los ritos ancestrales en los cuales aunaban las fuerzas de exaltación del sexo y de la muerte.

Pero fue Allan Kaprov quien en 1958 utilizó por primera vez el término happening para designar una acción, vaticinaba el fin de la pintura y el surgimiento de un arte participativo en el que se conjugaron todos los sentidos y engloba multitud de materiales: una silla, luces, neones, agua, humo, comida, un perro y una multitud de cosas... que se complementaban con acciones insólitas. El azar también pasó a formar parte de los happenings como ingrediente fundamental. Kaprov llega a la formulación del happening como deudor de la pintura de acción y de las obras de ensamblaje que se utilizaron para configurar entornos. Su objetivo era crear espacios envolventes en los que se articulaban las pinturas-collages, los objetos con las acciones con la intención de generar empatía en el espectador.

Fue en 1965 cuando Kaprov publicó un libro titulado Assemblages, Environments and Happenings, en el que explicaba cómo se había llegado al puro accionismo, es decir al happening, partiendo de las obras de ensamblaje. Para ello desarrolló una técnica de acción-collage que al acumularlos generaba un enviroment que era un ambiente en el que involucra al espectador, incorporando elementos como la luz y el sonido, para atrapar psicológicamente al espectador y por último incorpora los happenings, que eran acciones colectivas. Con todo ello consigue derribar barreras, con la intención de que el arte se funda con la experiencia, en resumidas cuentas, con la vida.

Un artista clave es Wolf Vostell que aunque residía en España y era de origen alemán. Su obra era participativa, realizaba acciones-decollage en la calle, en la que se invitaba a los transeúntes a participar buscando un significado en los carteles desgarrados. En los años sesenta fue un gran promotor del happening, como crítica social, denunciando la injusticia, la violencia y la deshumanización propiciada por el uso masivo de la tecnología, por consumir productos tecnológicos. En sus instalaciones utilizaba elementos industriales de desecho contrastados con elementos orgánicos como plantas o animales, porque para él el ser humano se mueve entre dos parámetros: la naturaleza y la cultura. En 1962 publicó Dé-collage, era la revista de difusión internacional de las ideas del grupo de acción Fluxus.

Y como integrante fundamental desde su creación del colectivo Fluxus es imprescindible nombrar a Josep Beuys. En los primeros años sesenta participó en numerosas acciones pero posteriormente se centró en su obra personal en la que articulaba de un modo indivisible su obra, vida y pensamientos. Josep Beuys junto a su obra ha sido un referente indispensable para el arte que se fué desarrollando a partir de la segunda mitad del siglo XX. En su obra buscaba la conquista de la libertad a partir de una redefinición poética de la relación del ser humano con la naturaleza, ésta como elemento animado.

Beuys con su obra proclama la fusión del arte con la vida para alcanzar el desarrollo hacia la libertad y la espiritualidad de la sociedad. Pretende desligar el arte de la academia, el arte lo extrapola a la política, a la economía y al pensamiento, porque para Beuys el verdadero capital del 
ser humano es su creatividad. A diferencia de las acciones y happenings del grupo Fluxus, que eran participativas, en las acciones de Beuys el público no era partícipe de la acción, muestra un papel de testigo de la acción en la que el artista que a modo de sumo sacerdote va desarrollando los acontecimientos como si de un Chamán se tratase.

Entre sus acciones son de especial interés destacar: Cómo explicar los cuadros a una liebre muerta (1965) o Me gusta América y le gusto a América, conocida como Coyote (1974).

Con sus acciones e instalaciones, Josep Beuys reclama un cambio de paradigma para el arte dirigiéndose más hacia un enfoque social.

Es cierto que existen otros artistas, a parte de los anteriormente citados, como: Gina Pane, Bruce Newman, Ana Mendieta, Judy Chicago, Marina Abramovic, Carolee Schneemann o Francis Alÿs...entre otros muchos, que han sido referentes indiscutibles para lo que hoy llamamos performance. Pero para no hacer demasiada extensa la lista y para poder concretar en el tema de la alimentación y la performance, se da paso en el siguiente apartado a conocer a artistas performers que se aproximan al tema alimentario.

\subsubsection{Artistas performers vinculados a la temática alimentaria}

Como ya se hizo referencia en el artículo titulado La alimentación actual desde la visión crítica de las humanidades (Faba, 2020) publicado en las actas de El gusto en el museo 2020, II Congreso internacional sobre patrimonio alimentario y museos, se ha realizado una selección de artistas que con sus performances hacen referencia al tema alimentario.

Artistas como: Martha Rosler, Patty Chang, Romira de Novellis, Rirkirit Tiravanija, Antoni Miralda o Àlvar Calvet. Cada uno de estos artistas han abordado la alimentación desde diferentes puntos de vista para reflejar sus diferentes inquietudes. La alimentación por tanto ha sido tratada desde perspectivas diversas: de género, el espacio doméstico, intercambios en las redes sociales o el despilfarro de comida.

De la artista Martha Rosler ha sido interesante destacar tres obras de videoperformance: $A$ Budding Gourmet, The East is Red, the West is Bending y Semiótica de la cocina. En su obra, Marta Rosler, sitúa a la mujer en el espacio doméstico que le ha sido reservado, la cocina. Espacio donde intenta con sus acciones deconstruir el papel tradicional de la mujer. La comida, la publicidad y los programas televisivos de cocina, en los cuales se transmiten los valores y pautas de género, reclaman la atención de la artista. Se establece una asociación entre arte y gastronomía y género. De un modo irónico proyecta la idea de la mujer que intenta conseguir un estatus social para su familia a través de recetarios de cocina sofisticada y de la adquisición de novedosos aparatos electrónicos. Emulando el mundo de la publicidad y los canales televisivos de cocina. (Rosler, 1975).

Otra artista que trabaja el tema de género asociado a la comida es Patty Chang. Es una artista multidisciplinar, que trabaja en performance, video, escritura o instalación. Su obra es el producto de la investigación de diversos temas complejos de una manera simultánea. Según se puede ver en su página web, podemos apreciar como en sus performances la artista visualiza la experiencia de lo femenino, estableciendo una conexión entre la comida y el cuerpo. Refleja conductas patológica, como la gula como reacción violenta al ideal de belleza que impone la sociedad. (Chang, 1998).

La performer Romira de Novellis, la conexión que se establece entre arte y gastronomía es de denuncia del despilfarro de alimentos, en un mundo globalizado y capitalista. En sus performances, 
Romira expresa a través de su cuerpo, articulando movimientos repetitivos, sus dudas, preguntas y críticas hacia una sociedad capitalista. Estableciendo su propio cuerpo como centro de su investigación. Entre las siguientes obras, cuyo tema en común es el despilfarro de la comida en los países de occidente: Tentativas de resurrección, La última cena, Bella ciao, Augurii e Infierno. (Novellis, 2019).

De Rirkrit Tiravanija es imprescindible hablar de su obra, ya que es una combinación entre fabricación artesanal de objetos, realización de performances y de instalaciones, recreando espacios que incentivan a que la gente interactúe, dejando que ocurran los acontecimientos. Su obra está marcada por la movilidad entre la cultura occidental y la cultura tailandesa. (Tiravanija, 1990).

Antoni Miralda es un artista multidisciplinar español. Desde la década de 1960, su trabajo ha desarrollado el objeto, el ceremonial, las acciones e intervenciones en el espacio público, la comida y el concepto Food Cultura. Algunas de sus esculturas son comestibles. Utiliza un lenguaje vibrante y participativo, basado en la celebración de los sentidos, del color, de la vida y de lo imaginario. (Miralda, 1960). Food Cultura es una fundación privada creada por el artista Antoni Miralda y la chef Montse Guillén. Han generado una plataforma donde se expone el concepto de "Food Cultura" desde la visión conjunta de la alimentación, la práctica artística y la exploración antropológica.

\subsection{Trabajo artístico personal y de investigación sobre la alimentación actual. Nuria Faba}

Como artista visual y multidisciplinar, incluyendo la performance en mis proyectos personales, he considerado conveniente poder mostrar mi trabajo artístico que se vale de las diferentes técnicas y disciplinas para abarcar proyectos cuyo tema principal es la alimentación. Mis proyectos son multidisciplinares porque recurro a diferentes técnicas y disciplinas según quiera hablar de un aspecto u otro de la alimentación. Por ello en mi obra se pueden encontrar desde esculturas, retratos en acuarela, vídeos interactivos, videoacción y performances siempre dentro del marco de la instalación. Realizo proyectos artísticos de implicación social, de género, con la naturaleza y con una marcada preocupación por la alimentación.

Las performance suelen ser participativas por lo menos en alguna parte de la misma. En las que el espectador, sin saberlo, es invitado a formar parte de la obra.

La alimentación actual, es tratada en mis proyectos desde la instalación audiovisual e interdisciplinar incorporando la performance como un ingrediente artístico muy potente que completa "la receta". Abordando diferentes aspectos relativos a la alimentación, como: la composición de los alimentos que consumimos, el origen, las labores de recolección, la compra, la contaminación del entorno por plásticos y microplásticos y el acto cotidiano de comer. Respondiendo a cuestiones tan relevantes como es: el qué, el cómo, el por qué, el para qué y el con quién de nuestro acto alimenticio. Realizando un guiño a los alimentos ecológicos, prácticas tradicionales de extracción y recolección de alimentos y a la resiliencia alimentaria y social, que gira en torno al acto cotidiano de comer.

A través de estos proyectos artísticos pretendo generar en el espectador una mirada crítica sobre la alimentación, al adentrarse en el recorrido envolvente de la instalación audiovisual e interdisciplinar y performática.

Los proyectos que considero más relevantes son los siguientes:

Naturalmente artificial es una instalación multidisciplinar realizada en 2014, que aborda el tema de la supremacía del ser humano a través de la problemática que suscita el uso de 


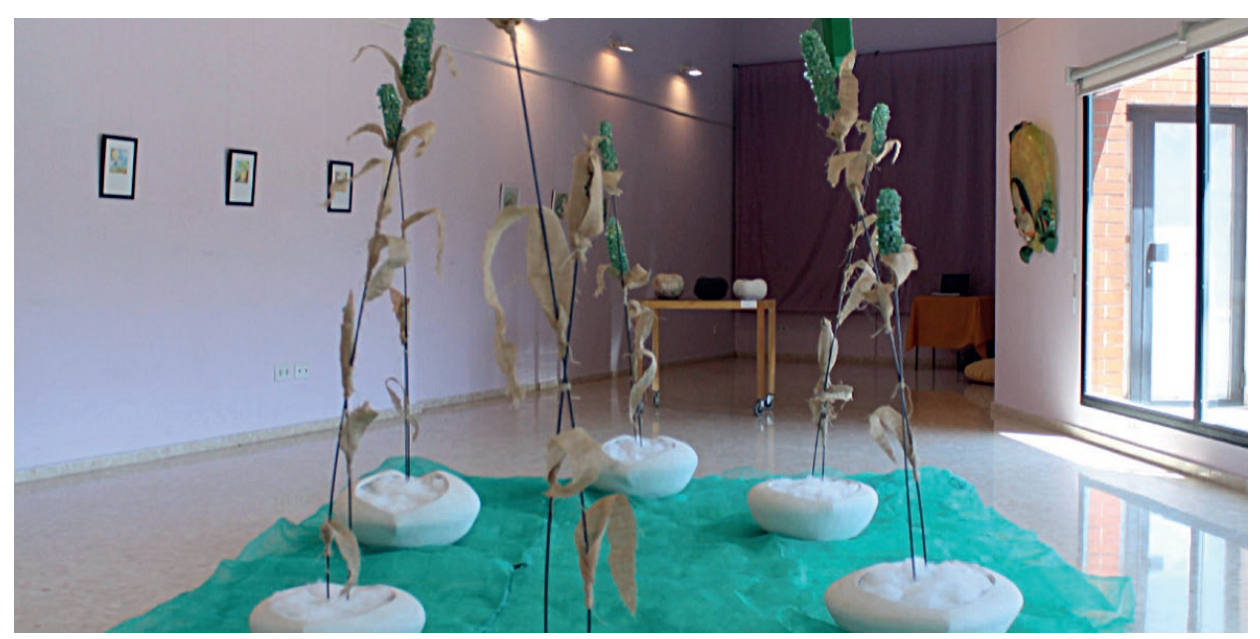

Figura 1. Nuria Faba, Naturalmente artificial, instalación, 2014. Fuente: Faba, N (2014).

transgénicos en la alimentación actual. El ser humano se otorga el derecho de crear y manipular todo lo que cae en sus manos de una manera poco responsable para la salud de las personas y del medioambiente.

ALIMENTARS-E, 2015, es una instalación escultórica y audiovisual, que pretende visualizar aspectos de nuestra cotidianidad como la publicidad, la compra o la acción de comer, para reflexionar acerca de nuestras elecciones alimentarias. Se abordan temas como la identidad, el consumo y la práctica alimenticia, con la expectativa de que como mínimo resulte inquietante.

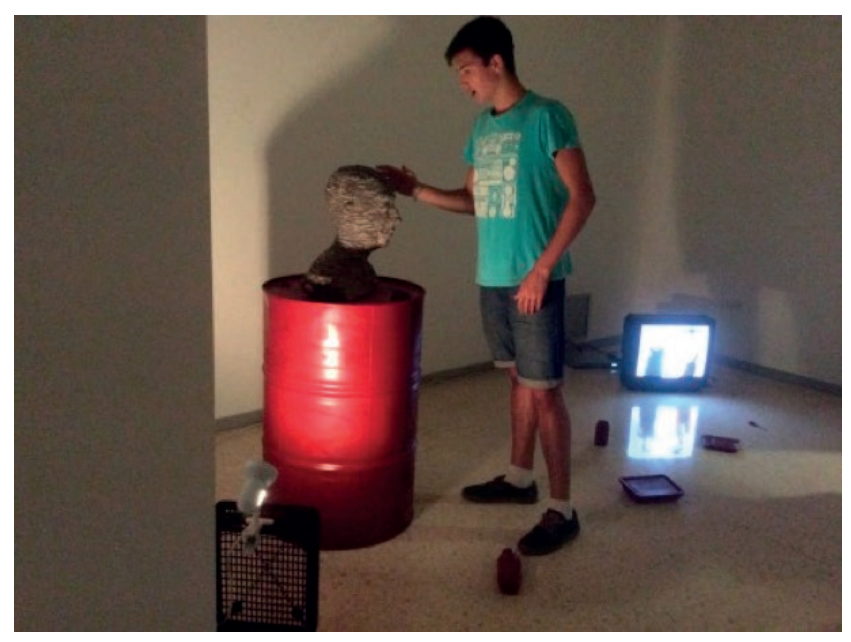

Figura 2. Nuria Faba, ALIMENTARS-E, instalación, 2015.

Fuente: Faba, N (2015). 

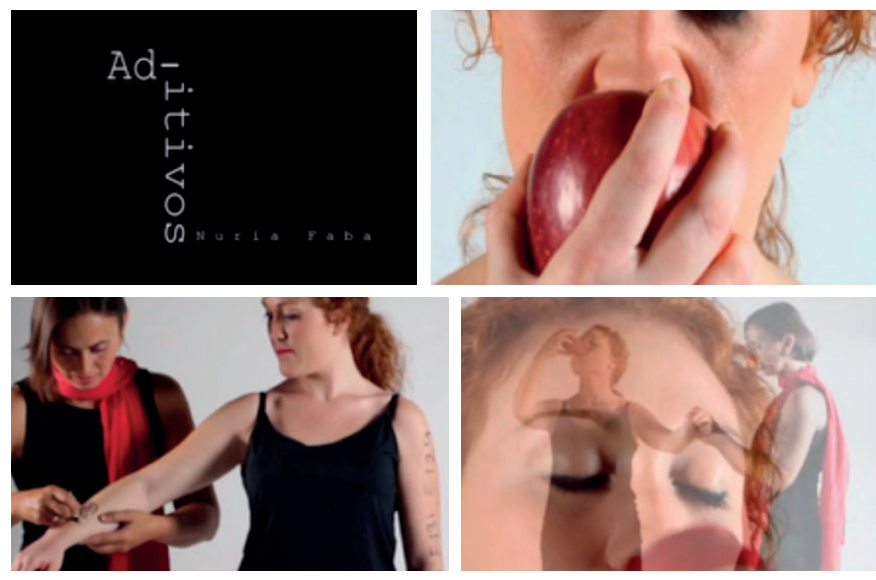

Figura 3. Nuria Faba, Ad-itivos, fotogramas de la videoperformance perteneciente a la instalación ALIMENTARS-E, 2015. Fuente: Molero, E (2015).

En este proyecto de instalación audiovisual se presenta una video performance titulada: Ad-itivos disponible en: https://www.youtube.com/watch?v=QcwFVFRahJs

A través de esta acción se pretende visualizar los aditivos alimentarios que se van acumulando en nuestro organismo durante la ingesta de alimentos procesados, frente a los beneficios de los alimentos naturales.

Polimorfosis, proyectando polímeros, es un proyecto de instalación audiovisual realizado en 2019. Su objetivo principal es hacer visible la contaminación que sufre el planeta a causa de los polímeros. Cómo afectan a la salud medioambiental y a los ecosistemas que lo habitan.

Se pretende mostrar cómo esta contaminación afecta a la tradición de la práctica pesquera local, a la vida marina y a la gente que habita el territorio, y hace hincapié en aspectos como: la

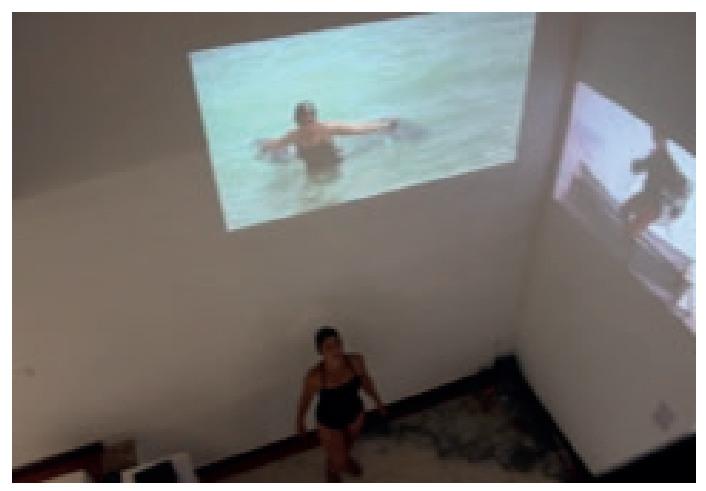

Figura 4. Nuria Faba, Bañista in site y Bañista outsite, video acción, Polimorfosis, proyectando polímeros, 2019. Fuente: Castellano, S (2019). 

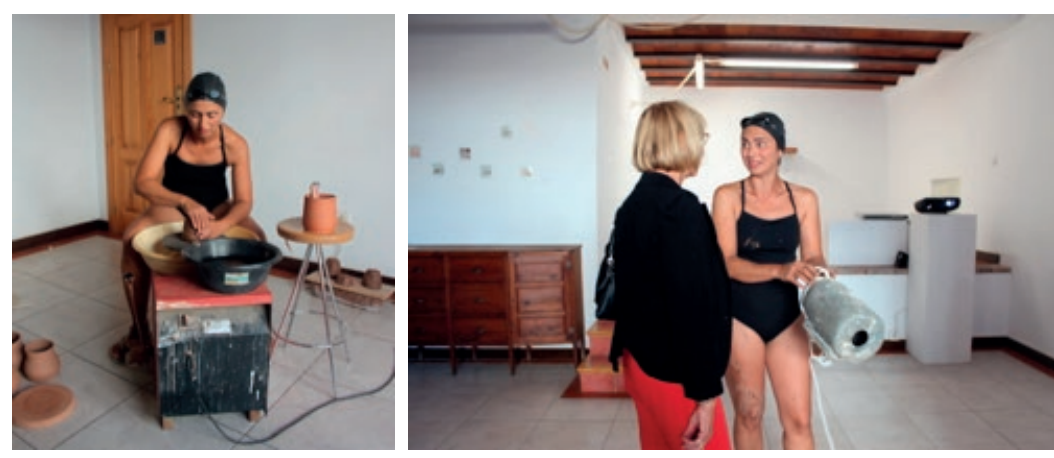

Figura 5. Nuria Faba, Calufos, performance, Polimorfosis, proyectando polímeros, 2019. Fuente: Castellano, S (2019).

repercusión en la salud de las diferentes especies que habitan el planeta, entre ellos el ser humano. Al ingerir estos plásticos y microplásticos, de forma accidental, pasan a formar parte de la cadena trófica. La instalación engloba esculturas, fotografía, vídeo acción y performance en directo.

Las piezas de vídeo acción Bañista in site y Bañista outsite, muestran la contaminación de nuestros mares y océanos por la presencia de plásticos y microplásticos que ingieren peces y moluscos y en último caso las personas llegando a formar parte de nuestra cadena trófica.

También se presentó una performance titulada Calufos, que hace referencia a las pulperas de cerámica que antiguamente se empleaban y cómo se ha ido sustituyendo por otras de plástico. En esta performance que se realizó el día de la inauguración, contó con la interacción del público, la acción consistía en hacer calufos a torno y luego trocearlos como si fueran anillas de calamar o ventosas del pulpo y la performer se dirige al público para que este le ayude a ponérselo por el cuerpo.

Inmersión Ama es un proyecto realizado en 2020 de instalación audiovisual y gráfico. Resultado de la investigación sobre la alimentación actual, que deriva en el modo de extracción de alimentos, como es el caso de las buceadoras Ama de Japón. Desde una visión femenina y ecológica.

En este proyecto se desarrolla la idea de la identidad femenina dentro de la labor pesquera tradicional. Se quiere visibilizar, la labor que durante siglos ha desempeñado la mujer como recolectora y procesadora de alimentos para el hogar. En esta instalación se fija el punto de vista en la sociedad oriental, concretamente en las buceadoras Ama de Japón. Buceadoras longevas que llegan incluso a la edad de 80 años en activo, realizando diariamente inmersiones para la extracción de distintos moluscos como ostras y orejas de mar, entre otros. Las buceadoras Ama realizan múltiples inmersiones diarias a pulmón, algunas de ellas llegan a bajar profundidades superiores a los $20 \mathrm{~m}$.

Desde una mirada ecológica se quiere hacer una llamada de atención y de denuncia por la contaminación medioambiental que sufren las aguas que conforman los mares y océanos del planeta. Debido a la presencia de elementos radioactivos y de metales pesados que pueden llegar a formar parte de la cadena trófica de moluscos, peces... y en última instancia de la de los humanos, por su ingesta.

Para ello la performer se hace pasar por una buceadora Ama y es grabada buceando a pulmón recolectando moluscos. 


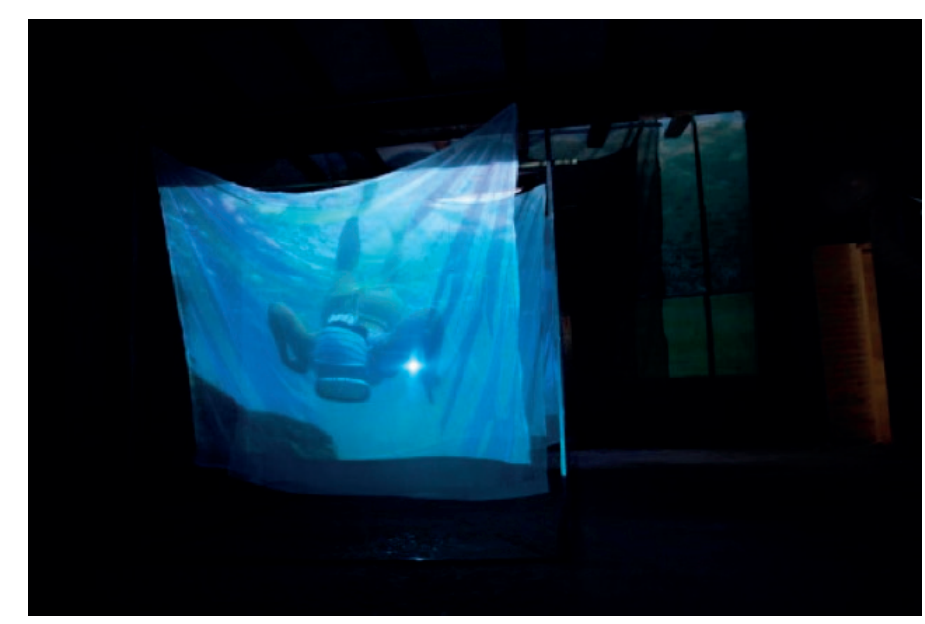

Figura 5. Nuria Faba, Ama II, videoperformance, Inmersión Ama, 2020. Fuente: Faba, N (2020).

Y como último proyecto recién presentado, en septiembre de 2021, está el proyecto que lleva por nombre ¿Comes conmigo?, es un proyecto de instalación performática, audiovisual y gráfica. En el que se conjugan distintas disciplinas como son: la video performance, el retrato en acuarela y la fotografía.

Con todo ello se pretende generar un marco interdisciplinar y envolvente, en el que se traslade al espectador a un ambiente de reunión en torno a una mesa y a la comida, haciendo que sea parte activa de la misma. En el que se pretende evidenciar el qué, el cómo, el por qué y el con quién, de la alimentación actual. Se presenta una mesa en la que ha acontecido una acción, un

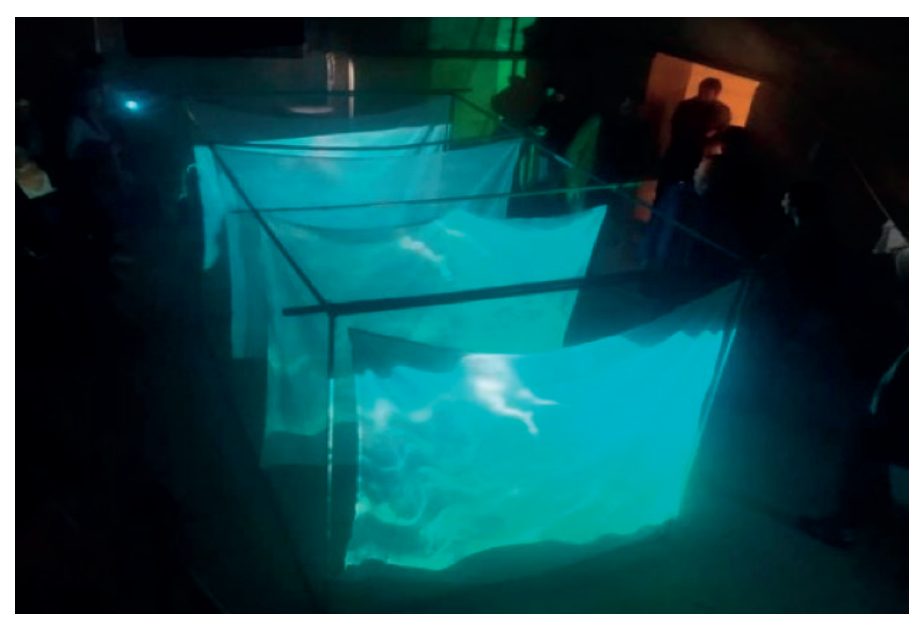

Figura 6. Nuria Faba, Ama II, videoperformance, Inmersión Ama, 2020. Fuente: Faba, N (2020). 

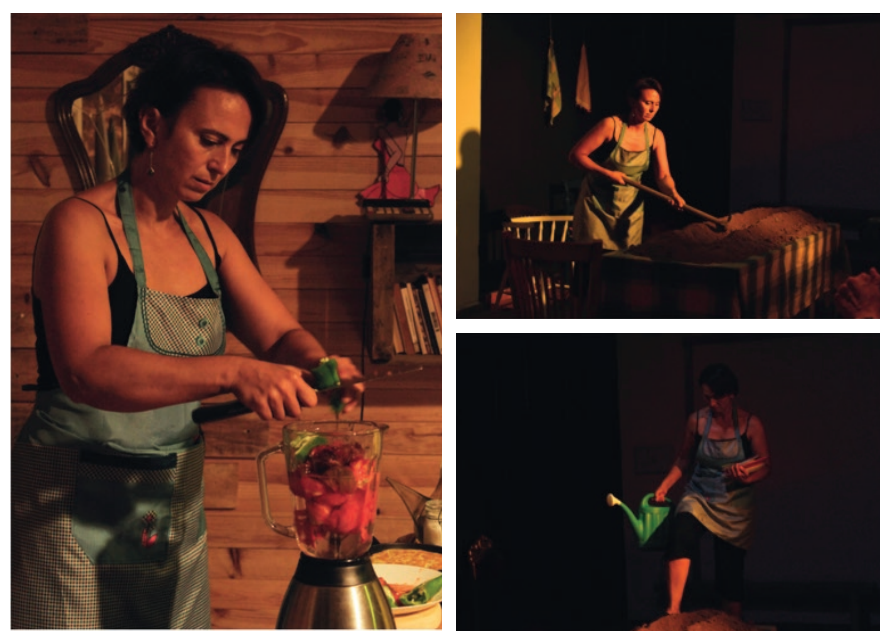

Figura 7. Nuria Faba, ¿Comes conmigo?, performance, documentación fotográfica, 2021. Fuente: Roque, J (2021).

ritual en torno al acto cotidiano de comer, esta acción se materializó en una performance que fue documentada en vídeo y en fotografía que posteriormente se muestra en el segundo acto: en la instalación performática, audiovisual y gráfica.

El acto cotidiano de comer es tratado desde la perspectiva del ritual, de la recolección, de la elaboración de alimentos, de la sociabilización, de la consciencia, saber qué se está comiendo, dónde, cuándo y con quién. Todo ello desde la visión artística de resiliencia alimentaria.
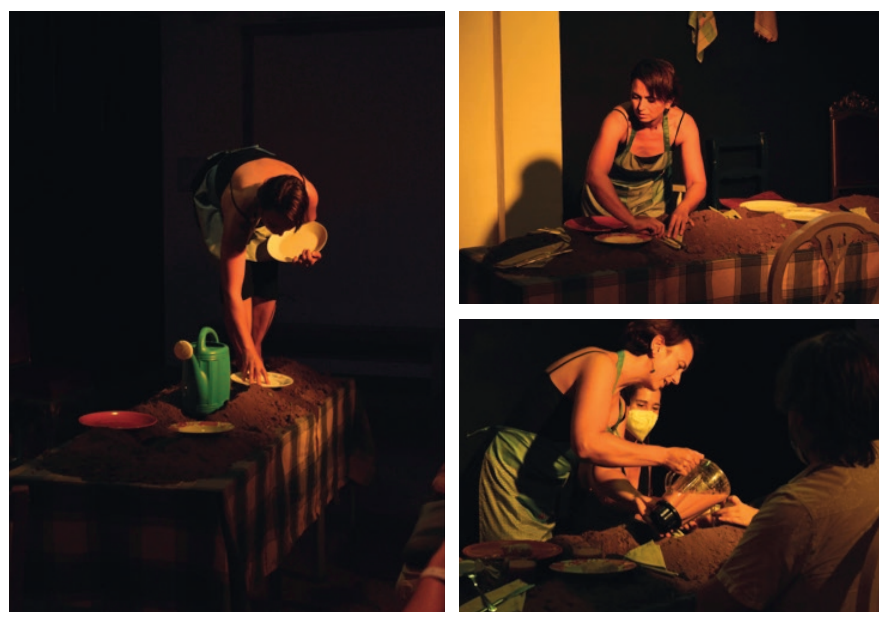

Figura 8. Nuria Faba, ¿Comes conmigo?, performance, documentación fotográfica, 2021. Fuente: Roque, J (2021). 


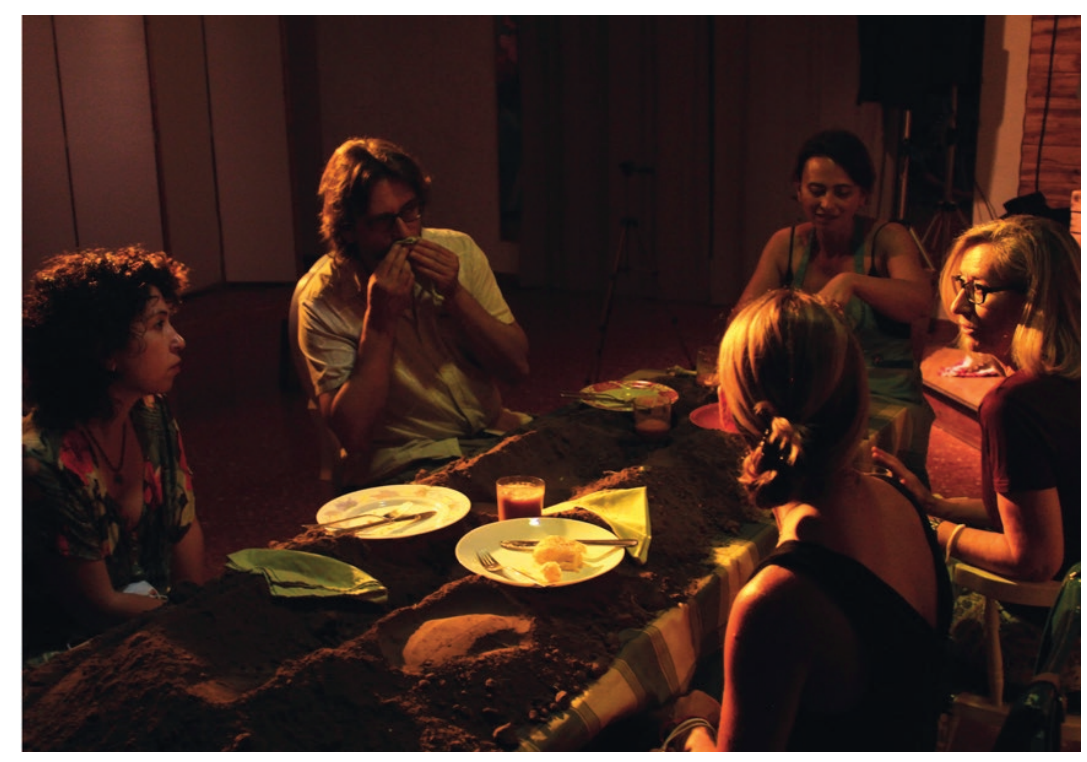

Figura 9. Nuria Faba, ¿Comes conmigo?, performance, documentación fotográfica, 2021. Fuente: Roque, J (2021).

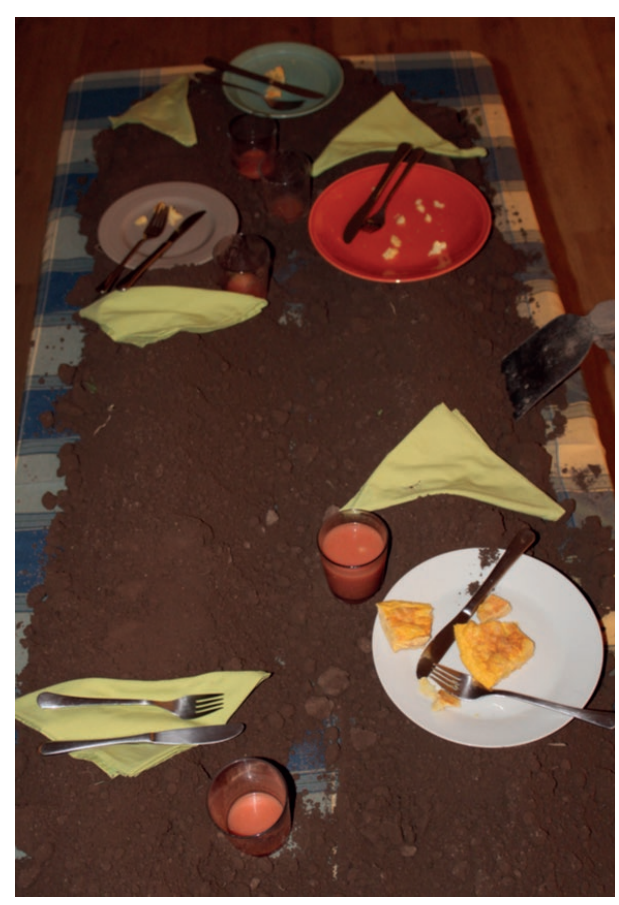

Figura 10. Nuria Faba, ¿Comes conmigo?, performance, documentación fotográfica, 2021. Fuente: Faba, N (2021). 


\section{Conclusiones}

A través del presente artículo, se ha podido reflejar la visión particular del arte respecto a la alimentación, en concreto desde la performance.

Mediante la Investigación y el análisis se ha conseguido abordar la performance desde su origen etimológico, definiendo conceptos clave para la comprensión del arte de acción, en concreto de la performance.

Se ha mostrado un panorama en el que la sitúa en el contexto de la historia del arte. Para ello se han recopilado y testimoniado fuentes referenciales que apoyan el discurso alimentario. Seleccionando obras de diferentes autores y disciplinas que constatan los cambios que se han producido entorno a la alimentación, el consumo de alimentos y el acto cotidiano de comer desde la mirada de la performance.

Se han presentado proyectos artísticos personales, cuyo tema principal es tratar de visualizar la alimentación actual, desde la visión de la videoinstalación, gráfica, escultórica y performativa. Fruto de la trayectoria artística e investigadora relativa a los estudios de licenciatura en bellas artes, máster en producción artística y doctorado en arte e investigación de la UPV.

\section{Referencias}

\section{Libro}

ALBARRÁN, J. (2019). Performance y arte contemporáneo, discursos, prácticas y problemas. Madrid Cátedra.

AUSTIN J. (1962). Cómo hacer cosas con palabras. Massachusetts: Harvard University Press.

FERRANDO, B. (2009). El arte de la performance, elementos de creación. Valencia: Mahali.

GOLDBERG, R. (1979). Performance. Live Art 1909 to the Present. New York: Harry N. Abrams.

GOLDBERG, R. (1988). Performance Art. From Futurism to the Present. NewYork: Harry N. Abrams.

GOLDBERG, R. (1996). Performance Art. Desde el Futurismo hasta el Presente. Barcelona: Ediciones Destino.

MARTÍNEZ, A. (2000). De Andy Warhol a Cindy Shermann. Valencia: Editorial UPV.

SCHECHNER, R. (2002). Performance Studies. An Introduction. London: Routledge.

\section{Página web}

MARTHA ROSLER. <http://www.martharosler.net>[Consulta: 8 de septiembre 2021]

PATTY CHANG. <http://www.pattychang.com >[Consulta: 15 de septiembre 2021]

ROMIRA DE NOVELLIS. <https://www.romina-denovellis.com/infernovenice>[Consulta: 5 de octubre 2021]

\section{Blogs}

FABA MUÑOZ, N. (2014). <https://nuriafaba.tumblr.com> [Consulta: 10 de octubre 2021] 